\title{
J Point Elevation
}

National Cancer Institute

\section{Source}

National Cancer Institute. JPoint Elevation. NCI Thesaurus. Code C71030.

An electrocardiographic finding of a significant elevation above the baseline of the J point. (CDISC) 